論文

멀티카메라를 이용한 영상정보 기반의 소형무인기 실내비행시험환경 연구

원대연*, 오현동*, 허성식*, 박봉균*, 안종선*, 심현철**, 탁민제**

\title{
Vision-based Small UAV Indoor Flight Test Environment Using Multi-Camera
}

Dae-Yeon Won*, Hyon-Dong Oh*, Sung-Sik Huh*, Bong-Gyun Park*, Jong-Sun Ahn*, Hyunchul Shim** and Min-Jea Tahk**

\begin{abstract}
This paper presents the pose estimation of a small UAV utilizing visual information from low cost cameras installed indoor. To overcome the limitation of the outside flight experiment, the indoor flight test environment based on multi-camera systems is proposed. Computer vision algorithms for the proposed system include camera calibration, color marker detection, and pose estimation. The well-known extended Kalman filter is used to obtain an accurate position and pose estimation for the small UAV. This paper finishes with several experiment results illustrating the performance and properties of the proposed vision-based indoor flight test environment.
\end{abstract}

\section{초 록}

본 논문에서는 실내 공간에 설치된 복수의 카메라로부터 획득한 영상정보를 소형무인 기의 자세 추정 및 제어에 이용하는 시스템에 대한 연구를 기술하였다. 제안된 시스템은 실외 비행시험의 제한을 극복하고 효율적인 비행시험 환경을 구축하기 위한 것으로 무인 기의 위치 및 자세를 측정하기 위해 별도의 센서를 탑재할 필요가 없어 저가의 장비로 테스트베드를 구성할 수 있다는 장점을 갖는다. 시스템 구현을 위해 요구되는 카메라 보 정, 마커 검출, 자세 추정 기법을 소개하였으며 테스트베드를 이용한 실험 결과를 통해 제안된 방법의 타당성 및 성능을 보였다.

Key Words : Vision-based Control(영상기반 제어), Extended Kalman Filter(확장형 칼만 필터), Multi-Camera System(멀티카메라 시스템), Flight Test Environment (비행시험환경)

\section{I. 서 론}

일반적으로 소형무인기 개발 과정은 개념설계, 형상설계, 실물제작 및 비행시험 등의 복합적인

† 2009년 10월 15일 접수 2009년 11월 27일 심사완료

* 정회원, KAIST 항공우주공학전공 대학원

** 정회원, KAIST 항공우주공학전공

교신저자, E-mail : mjtahk@fdcl.kaist.ac.kr

대전광역시 유성구 과학로 335
과정을 포함하고 있기 때문에 하나의 소형무인기 가 완성되기까지 많은 시간과 비용을 필요로 한 다. 특히 소형무인기는 동특성 및 공력특성의 정 밀한 모사가 어렵기 때문에 비행시험을 통한 검 증이 개발 과정에서 중요한 부분을 차지하게 된 다. 대부분의 소형무인기 비행시험은 실외에서 수행되고 있는데 이 과정에서 환경적인 요인의 제약으로 개발 일정이 지체되거나 추락으로 인해 상당한 비용손실을 입기도 한다. 
이와 같은 맥락에서 소형무인기를 위한 실내비 행시험환경이 다양한 방식으로 연구되고 있는데 대표적인 연구사례는 MTT ACL에서 개발한 RAVEN(Real-time indoor Autonomous Vehicle test ENvironment) 시스템이 있다[1]. RAVEN 시스템 은 모션캡쳐에 사용되는 비콘 센서를 소형무인기 에 응용한 것으로 비행체에 부착된 마커를 인지하 여 위치 및 자세를 측정한다. 이 시스템은 $1 \mathrm{~cm}$ 이 내의 높은 정밀도를 갖고 있으며 복수의 비행체를 쉽게 운용할 수 있지만 고가의 장비를 이용하여 구축해야 한다는 부담이 있다. 국내에는 생산기술 연구원에서 INS, Sonar, 영상 센서를 통합하여 소 형무인기의 위치를 인식하는 기술에 대해 연구를 수행한 사례가 있다[2]. 생산기술연구원의 위치 인 식 시스템은 저가의 장비로 시스템을 구축할 수 있지만 실험 공간에 설치된 지상 카메라와 소형무 인기에 탑재된 영상 시스템을 모두 이용하여 각각 에 설치된 마커를 인지하는 방식이기 때문에 비콘 센서를 이용하는 경우보다 상대적으로 정밀도가 낮고 시스템을 확장하는데 어려움이 있다.

본 논문에서는 실외 비행시험의 한계를 극복하 고 효율적인 비행시험을 달성하기 위한 방법으로 복수의 카메라로 구성된 실내비행시험환경을 제안 하였다. 이는 실내 공간에 설치된 복수의 카메라 에서 얻어지는 영상정보를 통해 소형무인기의 위 치 및 자세 정보를 추정하는 시스템으로 실외 비 행시험에서 발생할 수 있는 손실을 최소화하고 효 율적인 성능평가를 가능하게 한다. 또한 제안된 방법은 위치 및 자세 측정을 위한 별도의 탑재센 서를 요구하지 않으므로 소형무인기 개발 과정에 소요되는 예산을 줄일 수 있다는 장점을 갖는다.

본 논문은 다음과 같은 내용으로 구성하였다. 먼저 멀티카메라를 이용한 실내비행시험환경의 구 성을 제안하고 구체적인 동작 방식을 설명하였다. 그 다음 영상정보를 해석하기 위한 카메라 보정, 마커 검출, 3 차원 위치 측정과 같은 영상 알고리 듬을 기술하였다. 그리고 소형무인기의 상태변수 를 추정하기 위한 확장형 칼만필터(EKF: Extended Kalman Filter)의 적용을 다루었다. 끝으로 제안된 방안의 타당성 분석 및 성능 평가를 위해 두 대로 구성된 멀티카메라를 이용하여 실내 공간에 시스 템을 구현하고 회전익 방식의 소형무인기를 이용 하여 자세 추정 및 제어 실험을 수행하였다.

\section{II. 본 론}

\section{1 실내비행시험환경 구성}

본 연구에서 제안하는 자세 추정 및 제어 시 스템은 Fig. 1과 같이 칼라 마커가 부착된 비행

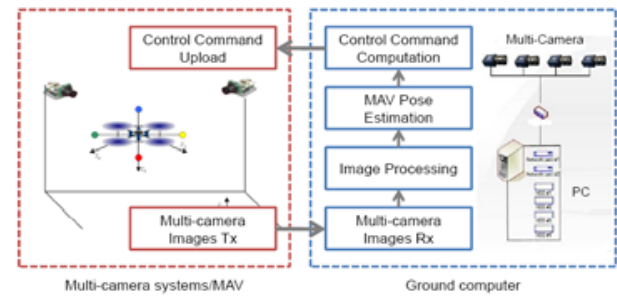

Fig. 1. Indoor flight test environment configuration

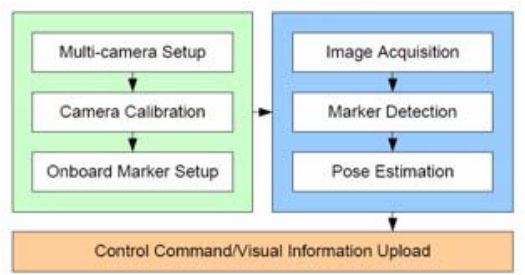

Fig. 2. Indoor flight test environment operation

체에 대한 영상정보를 제공하는 멀티카메라와 영 상처리를 수행하고 상태변수 추정 및 업로드를 담당하는 지상 컴퓨터로 구성되었다. 멀티카메라 는 외부 동기화 신호를 통해 각 카메라의 시야 (Field of View) 내에 있는 비행체의 영상을 지 상 컴퓨터로 출력하고 지상 컴퓨터는 입력받은 영상을 처리하여 마커의 위치를 산출한 뒤 비행 체의 상태변수를 추정하여 비행체로 송신하는 역 할을 담당한다.

실내비행환경 시스템의 동작은 Fig. 2에 표현 된 것과 같이 소형무인기의 상태변수를 추정하기 위한 멀티카메라 시스템 구축을 시작으로 카메라 보정, 칼라 마커 부착의 준비 작업을 거친다. 소 형무인기의 제어 실험이 시작되면 지상 컴퓨터에 서는 멀티카메라에서 입력받은 영상의 해석 과정 을 거쳐 소형무인기에 부착된 마커의 위치를 측 정한다. 소형무인기에는 십자 형태의 각 축을 따 라 Fig. 1과 같이 4개의 칼라 마커를 사용자가 설정한 위치에 부착함으로써 삼각측량법과 동일 한 원리로 소형무인기의 위치 및 자세를 측정할 수 있다[3].

\section{2 영상 알고리듬}

멀티카메라 시스템을 이용한 테스트베드는 카 메라 보정, 마커 감지, 3 차원 공간좌표 계산 알고 리즘 등의 개발이 요구된다.

카메라 모델

카메라는 기본적으로 3차원 공간상의 점을 2 
차원 평면 위의 점으로 투영하는 역할을 하며 이 관계는 행렬을 이용한 선형방정식으로 나타낼 수 있다[4]. 본 연구에서는 일반적으로 $\mathrm{CCD}$ 카메라 모델링에 사용되는 핀홀 카메라 모델을 이용하여 3 차원 공간상의 점과 그에 대응하는 2차원 평면 위의 점의 관계를 다음의 선형방정식으로 표현하 였다.

$$
\mathbf{x}_{2 D}=P \mathbf{X}_{3 D}
$$

3X4 행렬 $P$ 는 카메라 투영행렬(camera projective matrix)로 11 개의 자유도를 가지며 카 메라 중심 위치 $\left\{x_{0}, y_{0}\right\}$, 초점거리 $f$, 축 비율, 축 기울기 등의 센서 특성 및 3 차원 공간상의 위 치, 자세에 의해서 결정된다. 이러한 카메라 모델 은 Fig. 3과 같이 $C$ 를 원점으로 하는 좌표계로 표현할 수 있다. $X_{3 D}$ 는 3 차원 공간 동차 좌표계 (homogeneous coordinate) 상의 점 $\left\{X, Y, Z, W_{h}\right\}$ 를 $X_{2 D}$ 는 2차원 영상 동차 좌표계 상의 점 $\left\{x, y, w_{h}\right\}$ 를 나타낸다.

카메라 보정 기법

카메라 보정은 멀티 카메라 시스템을 구성하 는 각 카메라의 투영행렬을 구하고 Fig. 3과 같 은 좌표계 시스템을 설정하는 과정이다. 카메라 보정 과정에서는 체스판과 같이 지정된 좌표값을 갖는 보정 물체를 이용하여 3 차원 공간상의 좌표 값과 그에 대응하는 카메라 2차원 영상 좌표값의 관계를 구한다. 실내실험환경에서 각 카메라는 위치와 방향이 고정된 상황에서 동작하므로 카메 라 보정은 각 카메라에 대해 초기 설치 시에 한 번만 수행하여 결과를 저장한다. 카메라의 위치 및 자세 변경 시에는 사전에 계산된 각 카메라의 내부 파라미터(intrinsic parameter) 값은 유지하 고 원점에 대해 상대적인 값이 나타내는 외부 파

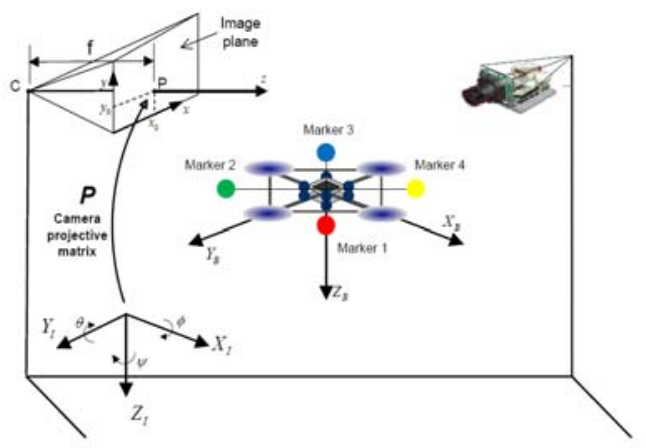

Fig. 3. Image, camera, body-fixed, and inertial coordinate systems 라미터(extrinsic parameter)만 추가로 산출한다. 일반적인 카메라 보정 기법의 기본 원리인 Direct Linear Transformation(DLT) 방법은 각 대응점에 대해 식 (1)로부터 식 (2)의 선형 방정 식을 유도하여 카메라 투영행렬을 계산한다[4].

$$
\left[\begin{array}{ccc}
\mathbf{0}^{T} & -w_{h i} \mathbf{X}_{3 D i}^{T} & y_{i} \mathbf{X}_{3 D i}^{T} \\
w_{h i} \mathbf{X}_{3 D i}^{T} & \mathbf{0}^{T} & -x_{i} \mathbf{X}_{3 D i}^{T}
\end{array}\right]\left(\begin{array}{l}
P^{1} \\
P^{2} \\
P^{3}
\end{array}\right)=A\left(\begin{array}{l}
P^{1} \\
P^{2} \\
P^{3}
\end{array}\right)=\mathbf{0}
$$

$P^{i T}$ 는 카메라 투영행렬 $P$ 의 $i$ 번째 행이며 $n$ 개의 대응점으로 카메라를 보정하는 경우 $A$ 는 $2 n \times 12$ 행렬이 된다. 투영행렬은 자유도가 11 이 므로 식 (2)의 해를 구하기 위해서는 최소 6개 이상의 대응점들이 필요하며 최소자승법을 이용 하여 해를 구할 수 있다.

본 연구에서는 카메라 보정을 위하여 위와 같 은 원리를 응용한 Zhang의 연구를 기반으로 MATLAB 환경에서 작성된 Camera Calibration Toolbox를 사용하였다 $[5,6]$. 이 방법은 평면 보 정 물체에 대해 다양한 각도에서 획득한 영상으 로부터 각 카메라의 내부 파라미터를 미리 산출 하고 3차원 투영행렬을 구할 때 이용한다. 이 방 법을 이용하면 Fig. 4와 같은 평면 보정 물체를 통해 멀티카메라를 보정하고 관성좌표계를 설정 할 수 있다. 일반적으로 멀티카메라 관성좌표계 의 원점은 평면 보정 물체의 모서리 중 하나로 선택하고 $X-Y$ 평면이 보정 물체 평면상에 위 치하도록 Fig. 4(b)와 같이 좌표계를 설정한다.
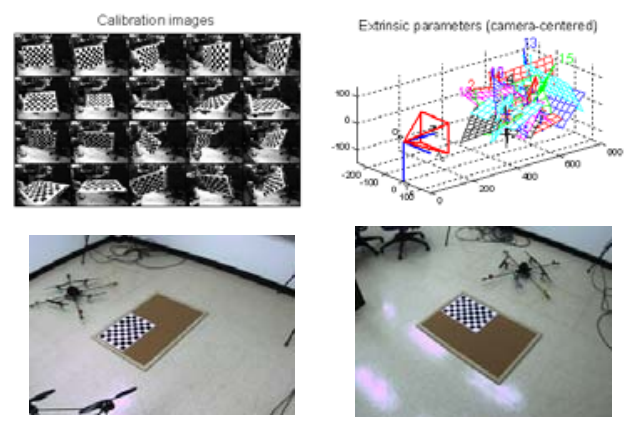

(a) calibration images
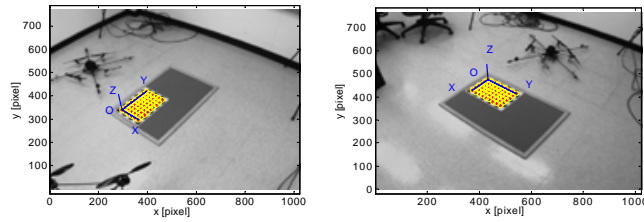

(b) coordinate system setting

Fig. 4. Multi-camera calibration 
3차원 위치 측정 (Linear Triangulation Method)

멀티카메라를 구성하는 각 카메라의 투영행렬 이 얻어지면 이를 바탕으로 범위 내 비행체의 마 커에 대하여 3 차원 공간 좌표를 계산하게 된다. 따라서 3차원 공간 좌표의 기준이 되는 보정 물 체의 정밀도와 보정 기법의 정확도가 테스트베드 의 성능에 결정적인 영향을 미친다. 3 차원 위치 측정 기법은 DLT, Iteration의 2가지 과정으로 나 눌 수 있다. 2대의 카메라로 멀티카메라 시스템 이 구성된 경우 식 (1)로부터 식 (3)과 같이 3차 원 공간좌표 $X$ 에 대한 선형 방정식을 유도하여 관성좌표계에 대한 마커의 위치를 구할 수 있다 [4].

$$
\left[\begin{array}{c}
x P^{3 T}-P^{1 T} \\
y P^{3 T}-P^{2 T} \\
x^{\prime} P^{13 T}-P^{1 T} \\
y^{\prime} P^{13 T}-P^{12 T}
\end{array}\right] \mathbf{X}_{3 D}=0
$$

$\{x, y\}$ 는 첫 번째 카메라에 나타난 마커의 영 상 좌표계 상의 위치이고 $\left\{x^{\prime}, y^{\prime}\right\}$ 은 두 번째 카메 라에 나타난 마커의 영상 좌표계 상의 위치이다.

\section{마커 검출 기법}

마커 검출 기법은 소형무인기에 부착된 마커 를 카메라의 영상 입력을 처리하여 검출하고 2차 원 영상 좌표값을 연산하는 과정을 말한다. 마커 의 검출은 RGB 또는 $\mathrm{HSV}$ 색상정보를 기반으로 이루어지므로 색상정보의 특성이 두드러지고 비 행체에 부착이 용이하도록 가볍게 제작해야 한 다. 또한 검출 알고리즘이 효율적으로 동작하려 면 조도와 같은 외부 실험 환경도 고려해야 한 다. 본 연구에서는 RGB 색상기반의 이진화 방법 을 이용하여 소형비행체에 부착된 4 개의 칼라 마 커(Red, Green, Blue, Yellow)를 검출하도록 하였 다. 영상에서의 각 픽셀은 0 에서 255 까지 강도를 가진 RGB 색공간 내에 존재하여 $\left(R_{i m}, G_{i m}, B_{i m}\right)$ 값으로 표현할 수 있으며 식 (4)와 같은 조건식 을 만족하는 픽셀을 이진화하여 각각의 칼라 마 커로 인식한다.

$$
\begin{aligned}
& \left\{\left(R_{i m}, G_{i m}, B_{i m}\right)^{i} \mid\right. \\
& \quad\left(R_{i m}>K_{R R}^{i} R_{i m}+K_{R G}^{i} G_{i m}+K_{R B}^{i} B_{i m}+R_{\text {thresh }}^{i}\right) \\
& \cap\left(G_{i m}>K_{G R}^{i} R_{i m}+K_{G G}^{i} G_{i m}+K_{G B}^{i} B_{i m}+G_{\text {thresh }}^{i}\right) \\
& \left.\bigcap\left(B_{i m}>K_{B R}^{i} R_{i m}+K_{B G}^{i} G_{i m}+K_{B B}^{i} B_{i m}+B_{\text {thresh }}^{i}\right)\right\} \\
& \text { where } i=\{\text { red, green, blue, yellow }\}
\end{aligned}
$$

식 (4)에서 임계값 $\left(R_{t h r e s h}, G_{t h r e s h}, B_{t h r e s h}\right)$ 와 계수
$\left(K_{R R}, K_{R G}, K_{R B}, K_{G R}, K_{G G}, K_{G B}, K_{B R}, K_{B G}, K_{B B}\right)$ 는 칼 라 마커의 특성에 따라 사용자가 설정하는 값이다. 이와 같은 RGB 조건식을 사용하면 고도 및 자세 변화로 마커의 색 정보가 다소 달라지더라도 원하 는 색상의 칼라마커를 원활하게 추출할 수 있다. 또한 조건식에 포함될 수치를 결정하기 위해 각각 의 마커 색상을 사전에 분석하는 과정에서 직관적 인 정보를 제공받을 수 있다는 장점을 갖는다.

색상정보로 걸러지지 않는 잡음 문제에 대해 서는 형태학적 영상 처리 기법인 침식(erosion), 팽창(dilation) 연산을 구현하여 해결하였다. 또한 검출 속도를 향상시키기 위해 각 마커별로 $\mathrm{ROI}($ Region Of Interest)를 설정하여 마커가 존 재할 확률이 높은 일정 구간에 대해서만 이진화 기법을 적용하도록 하였다. 구현된 알고리듬으로 얻어지는 영상 내 마커 검출 결과는 Fig. 5와 같 다. 본 논문에서는 실내실험환경을 적절하게 조 절할 수 있는 상황을 가정하고 있으므로 마커의 가림 현상이나 조도에 따른 마커 RGB 속성의 급 격한 변화는 고려하지 않았다.

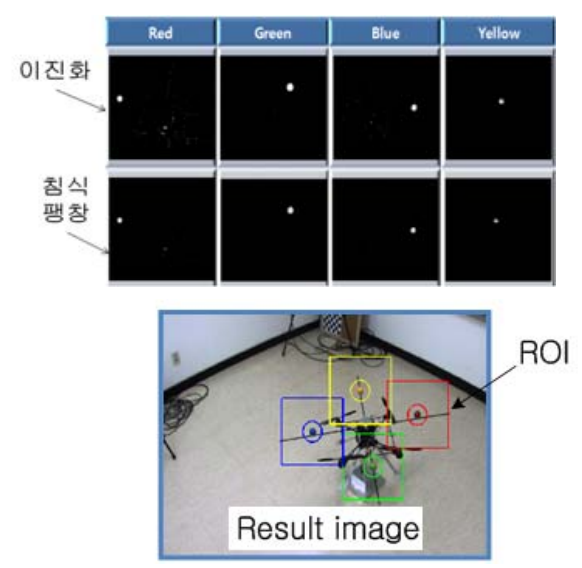

Fig. 5. Color marker detection
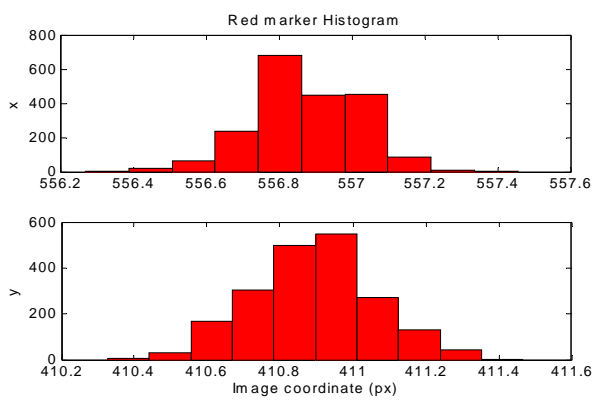

Fig. 6. Histogram of the camera image coordinates of red marker at fixed position 
Fig. 6은 마커 검출 기법을 이용하여 정지 상태 의 소형무인기에 부착된 Red 마커의 영상 좌표계 위치를 1 분 이상 측정한 결과이다. 히스토그램 곡 선은 측정값이 높은 정밀도와 정규분포에 가까운 잡음특성을 갖고 있음을 보여주고 있다. 이러한 영 상 좌표계 위치 측정값의 잡음 특성은 검출 기법, 카메라 성능, 조도의 변화 등에 영향을 받는다.

\section{3 위치 및 자세 추정}

본 장에서는 실내비행시험환경의 구성요소로 부터 위치 및 자세를 획득하기 위한 추정 기법을 설명하였다. 멀티카메라에서 얻어지는 측정값은 기체에 부착된 칼라 마커의 2차원 영상 좌표값이 며 소형무인기의 운동 모델은 위치, 속도, 자세 및 각속도의 상태변수가 포함된다. 본 연구에서 는 소형무인기의 운동 모델 및 칼라 마커의 측정 모델을 유도하고 확장형 칼만필터를 설계하여 상 태변수 추정하는 방식을 적용하였다.

\section{운동 모델}

소형무인기 운동 모델의 상태변수는 기체의 위치 $\{X, Y, Z\}$, 속도 $\{U, V, W\}$, 자세 $\{\phi, \theta, \psi\}$, 각속 도 $\{p, q, r\}$ 를 포함한다.

$$
\mathbf{X}=\left[\begin{array}{llllllllllll}
X & Y & Z & U & V & W & \phi & \theta & \psi & p & q & r
\end{array}\right]^{T}
$$

그리고 운동 모델은 식 (6)과 같이 관성좌표계에 서 표현된 6 자유도 비선형 운동방정식으로 유도 할 수 있다[7]. 이때 제어 입력인 힘과 모멘트에 대한 정확한 정보를 알 수 없는 상황이므로 힘은 중력과 평형을 이루며 모멘트 입력은 없다고 가 정하였다. 불확실성은 평균이 0 이고 크기 $Q$ 의 분산을 갖는 백색 가우시안 잡음으로 가정한다.

$$
\dot{\mathbf{X}}=f(\mathbf{X}, u)+w, \quad w \square N(0, Q)
$$

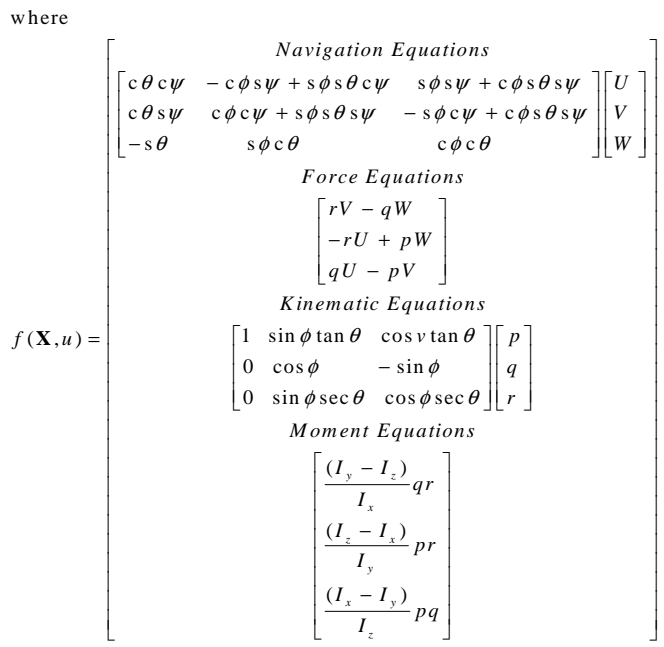

\section{측정 모델}

Fig. 3 과 같이 소형무인기에 부착된 4 개의 칼 라 마커 위치는 2 대로 구성된 멀티카메라를 통해 측정된다. 이 측정값은 각 카메라의 영상에 칼라 마커가 맺히는 2 차원 위치 정보이다. 이 때 측정 모델은 회전 변환 행렬 및 카메라 투영행렬을 사 용한 비선형 방정식으로 표현할 수 있다. 먼저 식 (7)과 같이 소형무인기의 중심 $\left(\tilde{X}_{c e n t e r}^{I}\right)$ 으로부 터 $i$ 번째 마커가 부착된 상대적인 위치 $\left(\tilde{X}_{p t, i}^{B}\right)$ 와 소형무인기의 자세각이 주어지면 각 마커 위치 $\left(\tilde{X}_{p t, i}^{I}\right)$ 가 결정된다.

$$
\tilde{\mathbf{X}}_{p t, i}^{I}=\tilde{\mathbf{X}}_{c e n t e r}^{I}+R_{B}^{I} \tilde{\mathbf{X}}_{p t, i}^{B}, \quad i \in(1,2,3,4) \text { marker }
$$

첨자 $I, B$ 는 각각 관성좌표계와 기체고정좌표계 를 나타내며 $R_{B}^{I}$ 는 기체고정좌표계에서 관성좌표 계로의 좌표변환행렬을 의미한다. 관성좌표계에 서 표현된 칼라 마커의 3 차원 위치 정보는 식 (8)과 같이 카메라 투영행렬을 거쳐 2차원 영상 정보로 표현된다.

$$
Z=\left[\begin{array}{llll}
Z_{1} & Z_{2} & Z_{3} & Z_{4}
\end{array}\right]^{T}
$$

where

$$
Z_{i}=\left[\frac{P_{c a m, 1}^{1} \tilde{\mathbf{X}}_{p t, i}}{P_{c a m, 1}^{3} \tilde{\mathbf{X}}_{p t, i}} \frac{P_{c a m, 1}^{2} \tilde{\mathbf{X}}_{p t, i}}{P_{c a m, 1}^{3} \tilde{\mathbf{X}}_{p t, i}} \frac{P_{c a m, 2}^{1} \tilde{\mathbf{X}}_{p t, i}}{P_{c a m, 2}^{3} \tilde{\mathbf{X}}_{p t, i}} \frac{P_{c a m, 2}^{2} \tilde{\mathbf{X}}_{p t, i}}{P_{c a m, 2}^{3} \tilde{\mathbf{X}}_{p t, i}}\right]^{T}
$$

이 때 $P_{c a m, j}^{k}$ 는 $j$ 번째 카메라 투영행렬의 $k$ 번째 행을 나타낸다. 위 과정을 정리하면 측정 모델은 다음의 비선형 방정식으로 표현할 수 있다.

$$
z=h(\mathbf{X})+v
$$

$\nu$ 는 측정값의 잡음이며 카메라 보정 과정에서의 bias 오차, $\mathrm{CCD}$ 센서 잡음, 측정 시간 지연 등을 통해 발생된다.

\section{추정 알고리듬}

소형무인기의 위치 및 자세 추정을 위한 알고 리듬은 일반적으로 널리 사용되고 있는 확장형 칼만필터를 이용하였다. 확장형 칼만필터는 다음 과 같이 prediction과 update의 두 단계를 거쳐 수행된다.

$<$ Prediction>

$$
\begin{aligned}
& F_{k-1}=\left.\frac{\partial f_{k-1}}{\partial x}\right|_{\hat{x}_{k-1}^{+}} \\
& P_{k}^{-}=F_{k-1} P_{k-1}^{+} F_{k-1}^{T}+Q_{k-1} \\
& \hat{x}_{k}^{-}=f_{k-1}\left(\hat{x}_{k-1}^{+}, u_{k-1}\right)
\end{aligned}
$$


$<$ Update $>$

$$
\begin{aligned}
& H_{k}=\left.\frac{\partial h_{k}}{\partial x}\right|_{\hat{x}_{k}^{-}} \\
& P_{k}^{+}=\left[\left(P_{k}^{-}\right)^{-1}+H_{k}^{T} R_{k}^{-1} H_{k}\right]^{-1} \\
& K_{k}=P_{k}^{+} H_{k}^{T} R_{k}^{-1} \\
& \hat{x}_{k}^{+}=\hat{x}_{k}^{-}+K_{k}\left[z_{k}-h_{k}\left(\hat{x}_{k}^{-}\right)\right]
\end{aligned}
$$

$F_{k-1}$ 과 $H_{k}$ 는 각각 운동 모델과 측정 모델의 Jacobian 행렬이며 $P_{k}$ 는 상태 추정 오차의 공분 산 행렬을 나타낸다.

\section{4 테스트베드 실험 결과}

본 장에서는 제안된 방식으로 구성된 실내비 행시험환경을 소개하고 상태변수 추정 및 자세 제어 실험 결과를 도시하여 성능을 검증하였다.

\section{시스템 구성}

본 실내비행시험환경을 구성하는 시스템의 사 양은 Fig. 7 및 Table 1과 같고 이 테스트-베드를 MATRIX(Multi-Agent Test-bed for Real-time Indoor Xperiment)로 명명하였다. 또한 Fig. 8과 같은 지상 제어 시스템을 만들어 각 카메라를 통 해 얻어지는 영상의 마커 검출 성능, 상태변수 추정 결과, 탑재센서(AHRS)의 데이터 등을 모니 터링하고 제어 명령을 전송할 수 있도록 하였다. 그리고 지상 컴퓨터에서 수행되는 영상정보의 데 이터 처리 시간은 Table 2에 나타내었다. 따라서 지상컴퓨터에서 산출된 영상정보 처리 결과는 약 $30 \mathrm{~Hz}$ 속도로 소형무인기에 전송할 수 있다.

Table 1. MATRIX specification

\begin{tabular}{c|c}
\hline \hline \multicolumn{2}{|c}{ MATRIX 구성 및 사양 } \\
\hline \hline 카메라 수 & Firewire CCD 카메라 2대 \\
\hline 카메라 해상도 & $1024 \mathrm{px} \times 768 \mathrm{px}$ \\
\hline 카메라 설 치 높이 & $1.4 \mathrm{~m}$ \\
\hline 카메라 FOV & $56.1^{\circ}(\mathrm{hor}) / 43.6^{\circ}(\mathrm{ver})$ \\
\hline 카메라간 거리 & $2.0 \mathrm{~m}$ \\
\hline 동기화 보드 & $\mathrm{NI} \mathrm{DAQ} \mathrm{PCl-6602}$ \\
\hline 지상 컴퓨터 & Core2 Quad CPU, 2.4GHz \\
\hline \hline
\end{tabular}

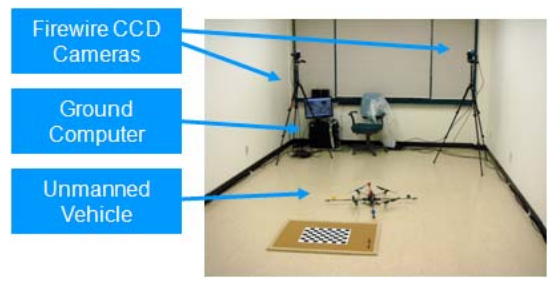

Fig. 7. Indoor flight test environment
Table 2. Data processing time

\begin{tabular}{c|c}
\hline \hline 프로세스 & 처리 시간 \\
\hline \hline 마커 검출 & $20 \sim 25 \mathrm{~ms}$ \\
\hline 상태변수 추정 & $3 \sim 5 \mathrm{~ms}$ \\
\hline 데이터 통신 & $5^{\sim} \sim 10 \mathrm{~ms}$ \\
\hline 계 & $28 \sim 40 \mathrm{~ms}$ \\
\hline \hline
\end{tabular}

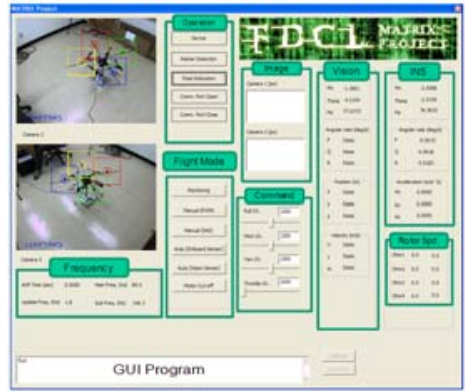

Fig. 8. Ground control system

\section{상태변수 추정}

Fig. 9는 4개의 칼라 마커를 부착한 소형무인 기가 수동으로 조종되는 상황에서 상태변수를 추 정한 결과이다. 마커 위치의 측정값 업데이트 주 기는 $30 \mathrm{~Hz}$ 이며 프로세스의 잡음은 $10^{-3}$ 크기의 분산을 갖는 백색 가우시안 분포로 가정하였다. 또한 필터의 추정 성능을 검증하기 위해 $\mathrm{DLT}$ 로 계산된 위치와 소형무인기 자세센서 측정값을 각 그래프에 함께 도시하였다. 영상정보를 기반으로 추정된 자세각과 탑재센서에서 측정된 자세각을 비교해보면 Table 3과 같은 정확도를 갖고 있다. 자세각 추정값이 높은 정밀도 보이는 것에 비해 편향 오차가 큰 이유는 멀티카메라 보정 시에 설 정하는 좌표계와 자세센서가 갖고 있는 좌표계의 정렬 오차 때문이다. 이러한 오차는 멀티카메라 보정 시에 사용자가 좌표계를 원하는 위치로 설 정을 변경함으로써 보상할 수 있다. 따라서 본 논문에서 제안한 실내비행시험환경은 멀티카메라 의 영상정보로부터 신뢰할 만한 소형무인기의 상 태변수 추정값을 제공함을 확인할 수 있다.

Table 3. Attitude estimation error

\begin{tabular}{c|c|c}
\hline \hline \multirow{2}{*}{ 자세각 } & \multicolumn{2}{|c}{$\mid$ 측정값-추정값| $(\mathrm{deg})$} \\
\cline { 2 - 3 } & 평균 & 표준편차 \\
\hline \hline$\phi$ & 1.04 & 0.611 \\
\hline$\theta$ & 2.60 & 0.508 \\
\hline$\psi$ & 0.951 & 0.625 \\
\hline \hline
\end{tabular}



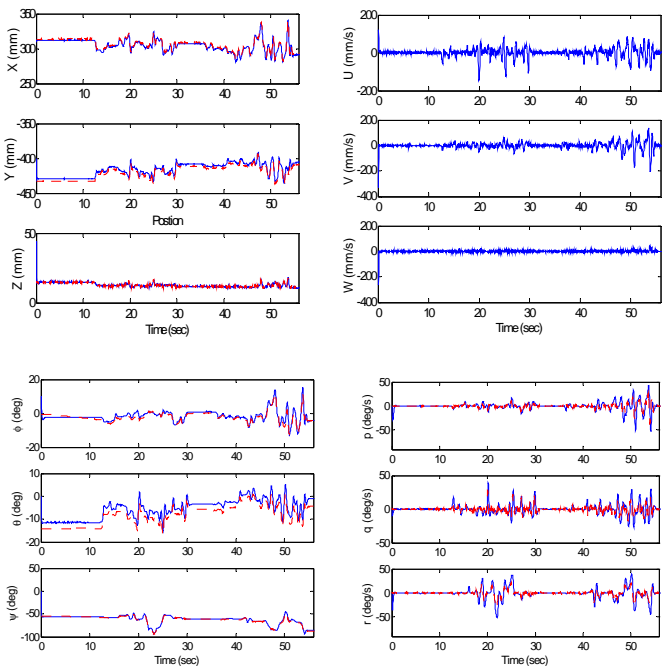

Fig. 9. UAV state estimation (solid: estimated, dashed: measured)

\section{자세 제어 실험}

본 절에서는 MATRIX를 이용하여 소형무인기 의 자세 제어 실험을 수행하고 제안된 방식이 비 행시험에 효과적으로 활용될 수 있음을 보였다. 먼저 자세 제어 실험을 위해 Fig. 10과 같은 3축 제어 장비를 이용하였다. 이 장비는 소형무인기 의 위치는 고정시키고 볼 베어링을 이용하여 3축 자세 제어를 가능하도록 설계된 것이다[8]. 자세 제어에 사용되는 상태변수는 자세 및 각속도이며 자세는 MATRIX에서 추정하고 송신된 자세 정보 를 피드백 하고 각속도는 탑재센서의 각속도 정 보를 피드백 하도록 하였다.

PID 구조의 자세 제어기는 호버링 상태에서 선형화된 모델에 대해 $6 \mathrm{~dB}, 45$ 도 이상의 게인 및 위상 여유를 확보하고 2초 이내의 정착시간을 갖 도록 설계하였다. 게인 튜닝을 거쳐 최종적으로 구현한 제어기를 기반으로 MATRIX를 통해 제어 실험을 수행된 결과는 Fig. 11과 같다.

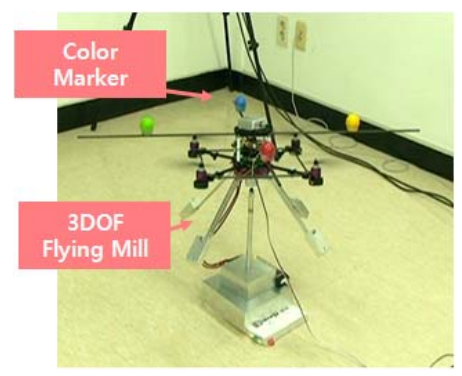

Fig. 10. 3-DOF Flying Mill
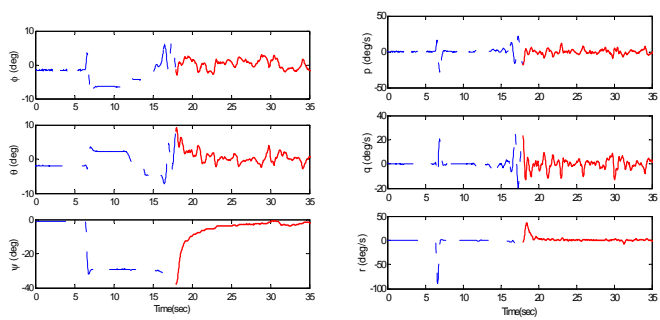

Fig. 11. Attitude stabilization (bold solid: autonomous control, dash-dotted: manual control)

Fig. 11의 자세 제어 실험은 수동 조종으로 로 터 각속도를 증가시킨 뒤에 18 초부터 35 초까지 호 버링 상태의 자세를 유지하도록 자동 제어 모드로 전환한 것이다. 이 결과로부터 멀티카메라를 이용 한 자세 추정값과 탑재센서의 각속도 정보만을 이 용하여 제어 실험을 가능함을 알 수 있다. 따라서 고가의 위치 및 자세 센서를 탑재하지 않고 저가 의 멀티카메라 시스템을 구축하여 실내환경에서 비행시험이 가능함을 확인할 수 있다.

\section{III. 결 론}

본 연구에서는 멀티카메라를 이용한 소형무인 기 실내비행시험환경에 대한 연구를 수행하였다. 이를 위해 복수의 카메라, 지상 컴퓨터, 칼라 마 커로 구성된 실내비행시험환경을 제안하고 카메 라 보정, 칼라 마커 검출 등의 영상 알고리듬과 확장형 칼만필터의 적용 방법을 기술하였다. 제 안된 시스템의 성능을 검증하기 위해서 2 대의 카 메라로 구성된 실내비행시험환경 테스트-베드를 구현하고 상태변수 추정 및 자세 제어 실험을 수 행하였다. 실험 결과를 통해서 멀티카메라의 영 상 정보를 이용한 소형무인기의 상태변수 추정 정확도가 높고 이를 자세 제어 실험에 안정적으 로 활용할 수 있음을 보였다. 본 논문에서는 2 대 의 카메라로 시스템을 구성하여 비행시험환경을 구축했으나 이를 3대 이상의 카메라를 이용하는 경우에도 기본 알고리듬은 동일하다. 향후에는 복수의 소형무인기를 실내비행시험환경에서 다루 기 위한 방안이 연구되어야 할 것이다.

\section{후 기}

본 연구는 한국과학기술원 국방무인화기술 특 화연구센터를 통한 국방과학연구소 연구비 지원 
과 두뇌한국(BK)21 사업의 협력으로 수행되었습 니다.

\section{참고문헌}

1) M. Valenti, B. Bethke, D. Dale, A. Frank, J. McGrew, S. Ahrens, J. How, and J. Vian, "The MIT Indoor Multi-Vehicle Flight Testbed", IEEE International Conference on Robotics and Automation, 2007, pp. 2758 2759.

2) M. Kang, S. Park, H. Lee, D. Won, and T. Kim, "Development of a Hovering Robot System for Calamity Observation", International Conference on Control, Automation and System, 2005, pp. 580 585.

3) 원대연, 허성식, 박봉균, 오현동, 심현철, 탁 민제, "멀티카메라 시스템을 이용한 실내 소형무 인기 테스트베드 예비 연구", 2008 한국항공우주 학회 추계학술발표회, 2008, pp. 1014 1018.
4) R. Hartly and A. Zisserman, Multiple View Geometry in Computer Vision, Cambridge University Press, 2003.

5) Z. Zhang, "Flexible Camera Calibration By Viewing a Plane From Unknown Orientations", International Conference on Computer Vision, 1999, pp. 666 673.

6) Camera Calibration Toolbox for Matlab, http://www.vision.caltech.edu/bouguetj/calib_d oc/\#system

7) H. Oh, D. Won, S. Huh, B. Park, D. H. Shim and M. Tahk, "Indoor UAV Pose Estimation from Multi-Camera System Using EKF", 2nd International Symposium on Unmanned Aerial Vehicles, Reno, Nevada, 2009.

8) 원대연, 최대형, 탁민제, "쿼드-로터 방식 비 행체 3자유도 제어 테스트베드 설계 및 제작", 제3회 군사용 로봇 워크샵, 2008, pp. 177 180. 